\title{
Study on Aesthetic Education Method in College PE Teaching Yiting Fan $^{1,}$ a \\ ${ }^{1}$ Xi'an Physical Education University, Xi'an, Shaanxi, 710000 \\ ${ }^{\mathrm{a}}$ email
}

Keywords: College Physical Education; Penetration; Aesthetic Education; Method

\begin{abstract}
Under the influence of new curriculum, College of physical education is standards have been effective changes, but due to the impact of teaching philosophy in the traditional sense, to promote sports teaching, whether in content or applied teaching, there are some problems. Therefore, in the actual development, teachers should not only focus on students' physical education, but also into the aesthetic education in Physical Education. This article has pay attention to College PE teaching aesthetic education methods for resolution.
\end{abstract}

\section{Introduction}

After graduating college students into the community will be faced with diverse challenges, which require students to maintain their own health, so it has an effective capital to solve the problem. The College of Physical Education is to ensure that students have effective physical and mental health of the basic work. But in the past, physical education and can not stimulate students' interest in learning, in order to the actual teaching work is not perfect, the quality of classroom teaching has not been improved. If the integration of aesthetic education in physical education, sport can improve the quality and efficiency of teaching, encourage students to better learn sports knowledge, training students to develop effective aesthetic ideas.

\section{The Link between Teaching and Aesthetic of College Sports}

Contact between teaching and aesthetic college sports are divided into the following points: First, to promote the aesthetic education of student sports movement more aesthetically pleasing. PE teachers in the implementation process of teaching can guide students to exercise, in the course of aesthetic education of students can develop spiritual beauty and promote health and beauty effective combination to achieve real sports teaching idea. Second, aesthetic innovation and encourage students to practice teaching basic sports knowledge. Not only to help students enhance their will to deepen students 'understanding of the technical capacity to enhance students' ability to judge and adaptability, it can also be based on their understanding of sports beauty and innovation. Enhance the aesthetic teaching quality in PE Teaching. Beautiful sports and body shape in order to guide the student interest, encourage students to independent study. In the process of guiding students in the sports associations were beautiful, contribute to its improvement in accordance with the principle of optimization, and change their original understanding of sports, to promote a more complete understanding of their sport [1].

\section{The Reason in Slow Development of Physical Aesthetic Education in the College Physical Education}

Physical Aesthetic Education in College Physical Education application process is slow and it is divided into the following main factors: first, the concept of college physical education teachers behind. Most colleges and universities in the implementation of physical education teaching, teachers for the aesthetic ideas of knowledge is not perfect, especially in sports education is not the main course, we do not pay attention to the appropriate teaching. College physical education course, the relative importance of sports training is, in particular, the ability of the athlete than the aesthetic ability to exercise more. Second, the PE teachers' quality is not high. Many PE teachers' knowledge 
of literacy teaching ability and ability to a certain extent the ability of teachers to students a lot of sports knowledge to implement effective teaching, a lot of emphasis on teaching physical education and competition in. Although the teaching of PE teachers of aesthetic awareness gradually increased, but also the practical application of lack of experience, in order to hinder the application of college sports Aesthetic Education. Third, college sports teachers still use conventional teaching concept. At this stage, in the implementation of physical education teaching, many teachers still from their own interests and teaching programs as the main basis, less the students' interest in learning and aesthetic concepts of focus, did not penetrate the "people-oriented" thinking in Physical Education, resulting in the lack of independent student learning concepts and learning mode.

\section{The College Aesthetic Education in PE Teaching Method}

In the process of implementation of Physical Education, the teacher of language skills is very important. In the classroom for knowledge about the movement to explain the actual teaching work an important part, so the PE teachers need to have a certain level of cultural knowledge and scientific skills to promote educational programs more relevant textbooks and teaching guide students to more in-depth understand the teaching of knowledge, combined with the associated movements and facial expressions to stimulate students' interest in learning, to enhance the focus of their learning in the classroom. Teachers based on actual teaching process decent language capabilities, rich curriculum, in order to stimulate students' interest in learning. Processes, especially during the operation of the demonstration, the teacher's action also requires decent shape, while demonstrating real action to students based on beautiful, skilled gesture. This will not only allow students an intuitive understanding of sports action, but also to enhance the students 'understanding of the operation of the aesthetic, in order to stimulate students' interest in learning, thereby enhancing the quality of physical education class [2].

During the process of physical education in the value of PE teachers themselves also have a certain impact on the teaching achievements. Teachers are key staff organize sports activities, which itself includes a patriotic spirit, but need to have the ability to innovate, adhere to the constant, strict demands on themselves at the same time adhere to struggle. Teachers should continue based on their own cultural competence and teaching students around the spiritual influence to promote the ability of students and teachers affected by the spirit and continuous improvement, while according to the students' exercise and improve their own values and aesthetic concepts.

In the process of implementation of Physical Education, the teaching environment is an important factor. Students learn the process of making sports, we need a clean learning environment, clear marking, perfect, rich teaching aids. Only high-quality teaching and learning environment is to encourage students to acquire effective knowledge and skills. In order to stimulate students' initiative, enthusiasm and creativity, PE teachers need to thoroughly implement the Sports Development Unit for three years, for a variety of materials, teaching programs were consolidated. In such an environment, it helps to teaching students practical PE teaching quick grasp of the relevant sports knowledge, and has an excellent teaching attitude, encourage students to obtain valid learning outcomes [3].

It is divided into the following main points: First, PE teachers need to focus on the aesthetic ideas, and applied in actual physical education, in order to promote learning, training, and other sentiments into the one, cultivate all-round development of students. Second, college physical education needs the most attention from the sports teaching students physical health problems, and guide students to establish and improve self-confidence, and knowledge of sports science teaching and the culture. Third, thoroughly implement the "people-oriented" concept, combined with the students 'interest in sport, focus on training students' interest, choose the student sports exercise conducted persist, prompting students to develop the habit of doing physical exercise every day.

\section{Conclusion}

In a word, the curriculum reform work is not a model and framework, combined with the actual 
situation requires school development, sports teachers and administrators learning combined with each other to work together to build in line with students' course work. In the embodiment College Physical Education reform requires changing ideas in the traditional sense, in sports technology to convert lifelong health education, provide effective services for professional teaching. Based on the development of colleges and universities teaching characteristics and student learning conditions, integration of the various professional hot, clear direction school physical education curriculum, thoroughly implement the principle of teaching, teaching full penetration of aesthetic ideas, encourage students to integrate physical education and better quality educational philosophy, training college students gradually into comprehensive development.

\section{References}

[1] Meng Fanhui, Zhang Rui. Thoughts of Aesthetic Education in College Physical Education Teaching infiltration [J]. Education, 2013,03.

[2] Chen Xin, Yu Yanglu. College PE teaching aesthetic education [J]. Sports World (Academic Edition), 2015, 01.

[3] Liu Peng. University PE teaching aesthetic education Suggestions [J]. Youth Sports, 2015, 04. 